\title{
MOLECULAR-GENETIC APPROACHES TO IDENTIFICATION AND TYPING OF PATHOGENIC CANDIDA YEASTS
}

\author{
Jitka Trtkova ${ }^{\mathrm{a}}$ and Vladislav Raclavsky ${ }^{\mathrm{b} *}$
}

\author{
a Department of Biology, Faculty of Medicine, Palacký University, Hnèvotínská 3, 77515 Olomouc, Czech Republic \\ b Department of Microbiology, Faculty of Medicine, Palacký University, Hnèvotínská 3, 77515 Olomouc, Czech Republic \\ e-mail:rac@tunw.upol.cz
}

Received: April 21, 2006; Accepted: June 5, 2006

Key words: Candida/Infection/Typing/Molecular methods/PCR/Melting analysis

Currently, invasive candidal infections represent an increasing cause of morbidity and mortality in seriously ill hospitalised patients. Because the accurate diagnosis of candidiasis remains difficult, a fast and reliable assay for characterization of fungal pathogens is critical for the early initiation of adequate antifungal therapy and/or for introduction of preventive measures. As novel molecular genetic techniques are continuously introduced, their role in the management of infectious diseases has also been growing. Today, molecular strategies complement conventional methods and provide more accurate and detailed insight. It can be expected that future technical development will improve their potential furthermore. In this article, we provide a critical review on the value and limitations of molecular tools in pathogenic Candida species identification and strain typing regarding their sensitivity, discriminatory power, reproducibility, cost and ease of performance.

\section{INTRODUCTION}

Candida yeast species belong to opportunistic pathogens; they are frequently found in samples from humans and from their environment and are capable of causing a variety of diseases. The mechanism of becoming pathogenic is still unknown in these common commensals, although impaired host defence mechanisms are considered to be fundamental ${ }^{1}$. Systemic infections caused by Candida spp. are becoming increasingly common in modern hospitals and frequently occur in patients with inherited and acquired immunodeficiencies, particularly in certain risk groups of patients, such as neutropenic patients, HIV-positive patients, and patients under intensive care. Since the number of these cases has risen in the last decades, the incidence of systemic candidiasis has been steadily increasing in parallel and it also has been associated with high rates of mortality of over $30 \%$ despite appropriate treatment ${ }^{2,3}$. Candida is now the fourth among microorganisms responsible for nosocomial bloodstream infections ${ }^{4}$. Survival of critically ill patients is dependent on prompt diagnosis and subsequent early initiation of antifungal therapy ${ }^{5}$. Therefore, rapid and reliable methods of detection are necessary to be developed and introduced.

Unfortunately, diagnosis of invasive candidiasis is still problematic, because clinical symptoms are non-specific and conventional assays are not satisfactorily precise and may take several days to obtain results. Blood cultures, which are assumed to be the most reliable marker of invasive candidiasis, are commonly negative, whereas positive cultures from other sites may represent colonization ${ }^{6}$. Also, blood culture requires 2-5 days for correct iden- tification. Molecular-genetic approaches, which rely on rapid detection of Candida yeasts nucleic acids in clinical samples, offer a promising alternative.

In addition to detection of Candida yeasts, species identification is very much in demand in some situations, because susceptibility to antifungal agents, probability of resistance development, and ability to cause disease can vary among different species. The most often identified species has always been Candida albicans, however the incidence of non-albicans Candida species has been increasing with the changing spectrum of patients and these species have also been associated with higher mortality ${ }^{7}$. $C$. glabrata and $C$. krusei show lower sensitivity to fluconazole in contrast to $C$. albicans, and emergence of secondary resistance in $C$. lusitaniae to amphotericin B has also been observed rarely ${ }^{8,9}$. C. parapsilosis persists in hospital environments, thereby enhancing the chance of nosocomial infection. It also commonly colonizes skin of patients and is able to form biofilms on plastics. This often results in candidaemia in patients with indwelling venous catheters.

Also, epidemiological investigations of infection outbreaks in hospitals are highly desirable to identify the source and route of infection to eradicate it. Such investigations require accurate strain typing, because in candidaemia it is problematic to distinguish between endogenous source of infection and infection transmitted exogenously from other infected patients or even health care workers ${ }^{10}$. Similarly to the species identification, phenotyping or genotyping can be applied in strain typing. Phenotyping methods characterize products of gene expression, thus reflecting genetic diversity. This is also 
their main shortcoming, because even minor variation in growth conditions can influence gene expression ${ }^{11}$, which leads to poor interlaboratory reproducibility. Phenotyping systems are also considered cumbersome, time-consuming and provide limited data for differentiation between epidemiologically unrelated isolates. In addition, some Candida species are capable of spontaneous switching between numbers of phenotypes ${ }^{12}$, so their phenotypic characteristics may be unstable or variable. In contrast to phenotyping, genotyping techniques detect differences in genetic information directly. Therefore, they are less sensitive to variations in growth conditions and also possess several other advantages over phenotyping procedures, e.g. higher discriminatory power, speed and reproducibility.

This review focuses on the vigorously fermenting field of molecular genetic approaches to Candida yeast identification and typing. Not only are new techniques and their modifications published at a growing pace, but also commercially available kits and other initiatives continually contribute to their standardization and ease of use, thus facilitating implementation of molecular approaches in routine use. It seems, that molecular techniques will soon revolutionise the identification of Candida species.

\section{A. DETECTION AND SPECIES IDENTIFICATION}

Techniques that rely on amplification of target yeast DNA are used almost exclusively for detection purposes, because the amount of yeast DNA available in a clinical sample is typically very low. These techniques include PCR and NASBA. Alternatively, yeast cells can first be multiplied during cultivation in blood culture bottles, and Candida DNA can then be detected in positive bottles by FISH with species-specific probes. This approach requires more time and is most probably less sensitive than PCR or NASBA. On the other hand, it may be more economic, because only positive bottles are examined. Also, results of FISH detection can later be verified by phenotyping of subcultured isolates, which are in addition available for strain typing. For general overview of detection techniques see also Fig. 1.

\section{PCR-based Methods}

The invention of PCR was a landmark in the progress of molecular microbiology and has had a substantial impact on the diagnosis of infectious diseases. The key strongpoint of these techniques consists in the amplification and detection of minute amounts of microbial nucleic acid in the background of host DNA. PCR-based methods can be appreciable especially when conventional methods are not available, are insensitive or slow.

\subsection{Target and primer selection}

Generally, two strategies of PCR target selection can be adopted. If species-specific sequences are selected as primer-annealing sites, PCR will enable highly specific detection of just one pathogenic yeast species. On the other hand, when universal panfungal sequences are targeted, PCR will result in amplicons in case any fungal DNA is present in samples. Candida-genus specific sequences can also be targeted to detect all Candida yeast species. If a broader spectrum of species is targeted, post-PCR analysis is necessary for subsequent species identification (see below). To ensure high sensitivity of PCR detection, primers should preferentially target multicopy genes. Also, high specificity should be secured by targeting sequences specifically found only in the pathogen of interest. The ribosomal RNA (rRNA) gene appears to meet both of these criteria. A tandem array of 50 to 100 copies of the rRNA gene can be found in the haploid genome of all fungi. This consists of the small subunit rRNA gene (18S), the $5.8 \mathrm{~S}$ gene and the large subunit rRNA (25S) gene, separated by the internal transcribed spacer regions, ITS1 and ITS2. While rRNA genes are highly conserved in fungi, ITS regions involve both highly variable and highly conserved areas ${ }^{13}$, thus allowing the generation of species, genus or fungus specific primer. The gene family of secreted aspartyl proteinases represents another group of sequences found in several copies in the yeast genome, which can serve as a target for PCR-amplification ${ }^{14}$. In addition, there are many examples of single-copy genes that can be caught by PCR and seem to be highly fungal specific, e.g. the P450 lanosterol- $14 \alpha$ demethylase gene ${ }^{15}$, actin gene ${ }^{16}$ and heat shock protein 90 gene $^{17}$.

\subsection{Nested PCR}

Nested PCR can be used to increase both the sensitivity and specificity of PCR detection. In this approach, two rounds of PCR are performed. In the first round, outer primers target a larger region for amplification. Amplicons from this round are then added as template into the second round reaction mixture, where inner primers target a fragment of the first round amplicon. Specificity of the assay is increased, because four primers have to anneal in an arranged fashion instead of just two in a single PCR. Sensitivity is increased, because addition of fresh reagents and dilution of first round amplicons in the second round mixture enables additional amplification of a fragment of the amplicons from the first round mixture. Two-rounds setting of nested PCR can also be used to combine the advantages of broad-range and species-specific targeting of yeast sequences. The outer primers can target universal sequences resulting in amplicons in a broad range of yeast species, followed by several parallel second round reactions with species-specific inner primer pairs. When second round primers are carefully designed to prevent interference, primer mixes can be used in a common reaction mixture to reduce costs, in an approach called multiplex PCR. Nested PCR approach was adapted for use in Candida species detection by Kanbe et al. ${ }^{18}$, and Bougnoux et al. ${ }^{19}$ On the other hand, the extreme sensitivity of nested PCR results in its major drawback - the occurrence of false-positive results mainly due to the cross-contamination with previously amplified products ${ }^{20}$, and also due to contamination with environmental microorganisms, or even contaminated commercially available reagents ${ }^{21}$. To 


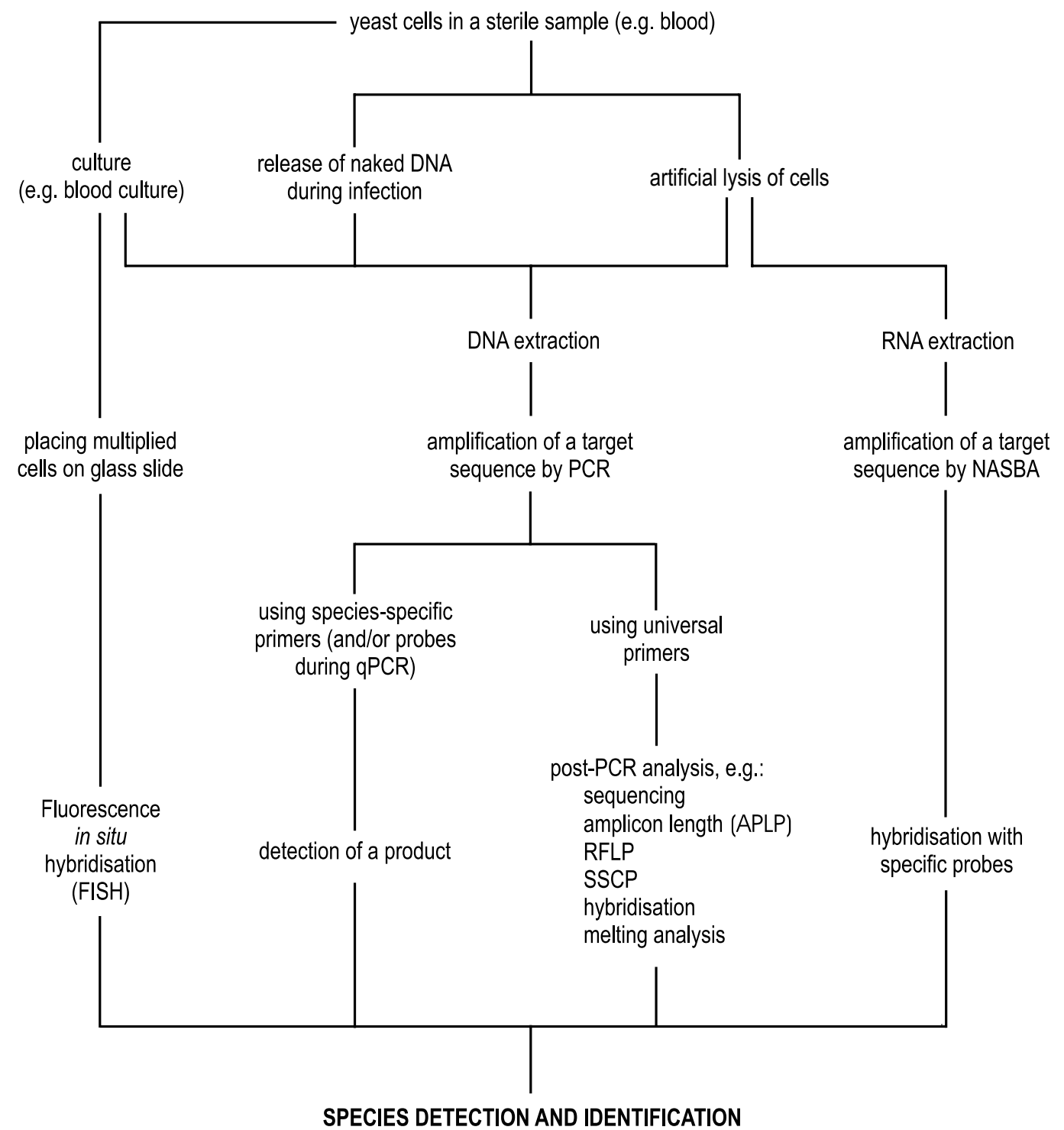

Fig. 1. General overview of detection and identification techniques.

avoid this pitfall, laboratories must follow stringent precautions such as establishing separate rooms and equipment for each step of the PCR and other procedures ${ }^{22}$.

\subsection{Real-time PCR}

The real-time polymerase chain reaction uses fluorescent reporter molecules to visualize the production of amplicons during each cycle of the PCR reaction. This is in contrast to endpoint detection in conventional PCR, where the amplicon is detected after completed amplification only. Real-time monitoring of amplification based on increase of fluorescence of reporter molecules enables quantification of the target DNA, because the timepoint at which the amplicons reach a specific fluorescence level during cycling corresponds with the starting amount of target DNA. This correlation is impossible in the case of conventional PCR, where the final amount of amplicons always reaches a uniform level due to inhibition of further amplification in the plateau phase of the reaction. The process of amplification can be monitored either using labelled probes which specifically hybridise to the newly formed amplicon molecules, or by staining newly formed double-stranded DNA molecules with non-specific dsDNA binding dyes (e.g. SYBR Green I, BEBO, LC Green or BOXTO). The use of probes increases the specificity of PCR, because an additional sequence homology between the amplicon and probe is necessary for successful reporting of amplification. When a dsDNA binding dye is used instead of a specific probe, melting analysis of the amplicon has to be performed subsequently to verify the identity of the amplicon. Sometimes, unambiguous differentiation between specific and non-specific products can be problematic. On the other hand, melting analysis can provide additional useful information about the amplified sequence. Traditionally, one has to choose between the use of a sequence-specific probe and a non-specific dsDNA binding dye, because of spectra overlap in fluorescent dyes used for labelling of probes and for dsDNA staining. Recently, however, the use of BOXTO dsDNA binding dye has been reported as compatible with the use of probes labelled by $\mathrm{FAM}^{23}$. 
The use of an integrated thermocycler/fluorimeter with highly efficient heat exchange mechanism has significantly shortened the turnaround time of real-time PCR. Both amplification and detection take place in the same closed vessel, reducing post-amplification manipulation steps and dramatically decreasing the risk of false-positive results. Despite greater start-up expense and the lack of standardization, the oncoming explosion of new chemistries and instrumentation, sensitivity, reproducibility and potential for high-throughput, will nevertheless make the real-time PCR attractive and indispensable for future diagnostic mycology.

Several studies have reported the identification of Candida species by targeting the rRNA gene complex using real-time $\mathrm{PCR}^{24-28}$. The wide variety of fluorescent dyes available makes it possible to amplify multiple templates in a single tube, as fluorescent dyes with different emission spectra may be attached to the different probes, providing the dyes are compatible with the excitation and detection criteria of the real-time cycler used ${ }^{29}$. Bu et al..$^{30}$ described the detection and quantification of five fungal species in a multiplex real-time PCR assay.

\subsection{Post-PCR analysis}

Whether conventional or real-time PCR is used, several options for post-PCR analysis are available to characterize the amplicon and conclusions can be drawn on its speciesspecificity, especially if universal sequences are targeted for amplification. Obviously, the only ultimate and most accurate way of post-PCR analysis is direct sequencing ${ }^{31}$. Although commercial systems are available ${ }^{32}$, this option is still too expensive and laborious for routine use. However, alternative sequencing techniques, e.g. pyrosequencing, are under continuous development and promise further reduction of costs in the future. All the other techniques of amplicon post-PCR analysis rely in some way on characterization of its sequence-related variability. The length of the amplicon can be roughly estimated by agarose gel electrophoresis, which represents the most simple and traditional technique of post-PCR analysis, also called Amplified product length polymorphism (APLP). More accurate length characterization of amplicons can be achieved by polyacrylamide gel electrophoresis, which can be automated in a capillary-based analyser ${ }^{33,34}$. (Marino 1994, Chen 2000). Restriction analysis of amplicons represents a rather cheap and elegant but laborious and more time-consuming technique ${ }^{35,36}$. Similarly, single-strand conformational polymorphism (SSCP) can be employed to evaluate sequence-based characteristics of amplicons ${ }^{37,38}$, but it is not widely used because of special expertise and labour needed for correct performance.

To avoid the time-consuming and laborious electrophoresis step, used traditionally in the above-mentioned techniques, two alternative approaches can be applied. Microtitration plate enzyme immunoassay (PCR-EIA) can be utilized as a user-friendly alternative, which also improves detection sensitivity ${ }^{39}$. Amplicons hybridise to two oligonucleotide probes, a biotin-labelled genus-specific probe and a digoxigenin-labelled species-specific probe, and the hybridisation complex is added into streptavidinecoated wells of a microtiter plate. The positive reaction is caught by peroxidase-conjugated anti-digoxigenin antibodies. Melting analysis of amplicons represents another recent promising choice, because of its simple, rapid and economic performance. It relies on staining of doublestranded DNA (amplicon) with a fluorescent dye, which is released from the structure once DNA strands are separated during denaturation (melting) with increasing temperature. The concomitant decrease of fluorescence can be followed by a fluorimeter, either embedded into a real-time PCR instrument or used as a separate melter instrument ${ }^{40}$. Characteristic melting curves are recorded, because the process of melting depends both upon the length of the amplicon and upon its sequence, where ATrich regions melt at lower temperatures, whereas GC-rich ones at higher temperatures. Use of melting analysis in post-PCR analysis of pathogenic yeasts' amplicons has not been reported yet. However, there is no doubt about its potential in this area, particularly since high resolution melting analysis (HRMA) and saturating dyes are now available ${ }^{41}$. The first use of HRMA in diagnostic microbiology was reported in mycobacteria recently ${ }^{42}$.

\section{Nucleic Acid Sequence Based Amplification (NASBA)}

NASBA is a specific and very sensitive RNA amplification technique, which exploits the action of three enzymes, i.e. reverse transcriptase, RNase H and T7 RNA polymerase, in an isothermal amplification process with cDNA as an intermediate ${ }^{43,44}$. For schematic overview of its reaction steps, see Fig. 2. In medically important fungi, conserved regions of the 18S rRNA gene can be targeted by the amplification ${ }^{45}$. Labelled oligonucleotide probes are then hybridised to an internal specific sequence of the Candida yeast species. Amplification and detection can be completed within few hours and the analysis has shown a detection limit of 1 CFU. NASBA has been evaluated to detect six various Candida species ${ }^{46}$. The main benefits of NASBA compared to PCR are no need of thermal cycling instrument and specific detection of living yeast cells, because RNA unlike DNA is rapidly degraded outside cells. The main disadvantage, which prevents more widespread use of NASBA, is the high price of the three enzymes mixture.

\section{Identification by Fluorescence in situ hybridisation (FISH)}

Fluorescent in situ hybridisation (FISH) with fluorescein-labelled oligonucleotide probes is a convenient way to detect yeasts without the need of pure culture. The employment of novel PNA (peptide nucleic acid) probes combines their high-affinity with advantages of targeting highly structured rRNA region, which has extended the potential of this method. Briefly, probes are hybridised to smears made directly from the contents of blood culture bottles on a slide, non-hybridised probes are washed out and slides are examined by fluorescence microscopy to reveal the presence of the organism. The sensitivity of the method has been estimated at least as similar to most results obtained by PCR-based assays ${ }^{47}$. Due to a simple 


\section{Forward primer anneals to a specific site of extracted RNA}

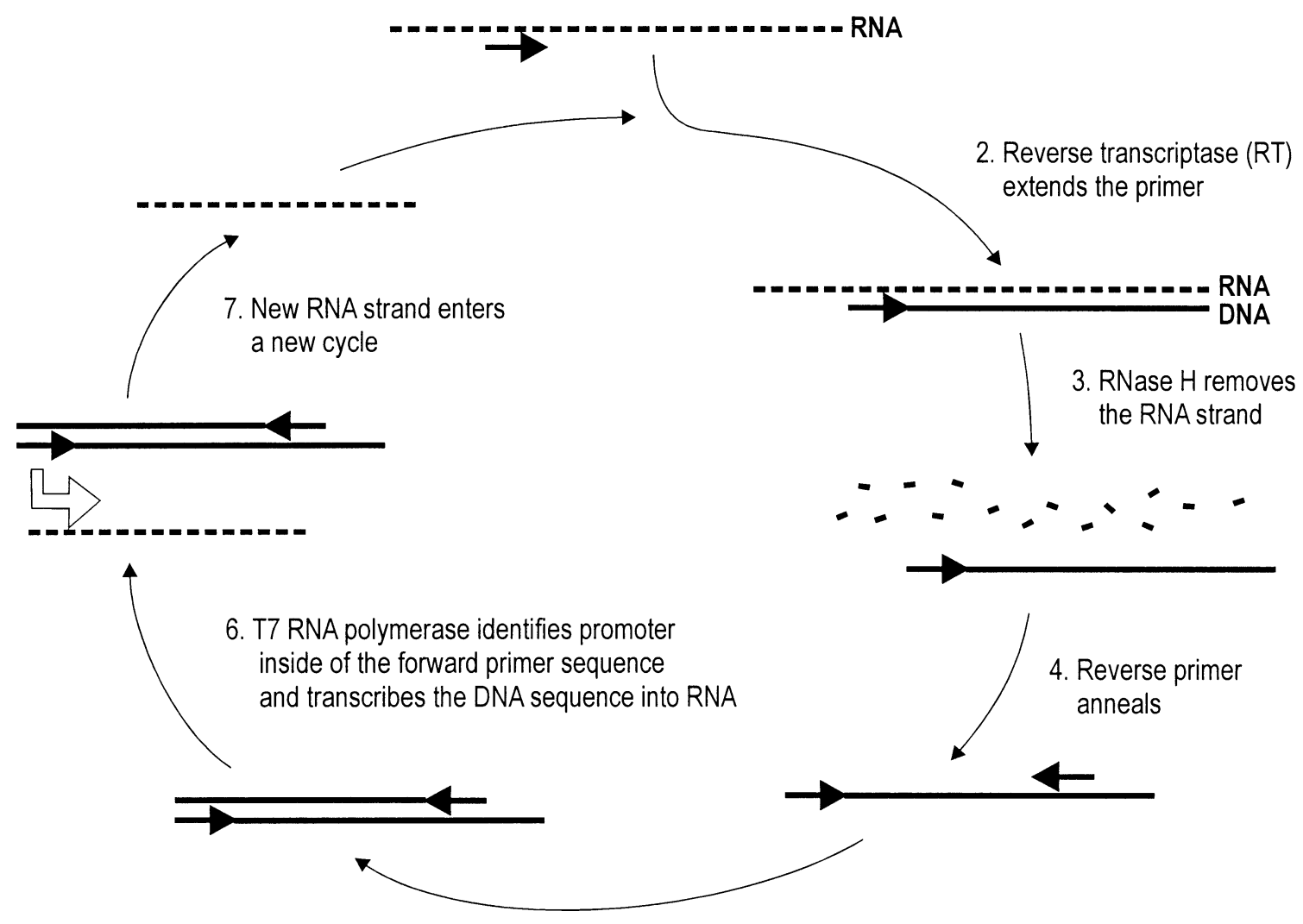

5. RT extends the primer

Fig. 2. Nucleic Acid Sequence Based Amplification (NASBA) reaction steps.

technical protocol with the exclusion of DNA extraction, the entire PNA FISH requires only 2.5 hours after a blood culture is designated positive by an automated blood culture system, the whole procedure is suitable for automation. FISH including probes specific for Candida species has been demonstrated to be a reasonable diagnostic tool for species identification ${ }^{48}$. PNA FISH has been developed to differentiate $C$. albicans from non-albicans Candida species $^{49}$, evaluated in a multicenter study ${ }^{50}$ and its implementation in hospital reduced antifungal drug expenses $^{51}$. The same group also conducted a PNA FISH assay to differentiate $C$. albicans from $C$. dubliniensis ${ }^{52}$.

\section{B. STRAIN TYPING}

In contrast to detection techniques, which target universal or species-specific sequences, strain typing aims to differentiate specific strains or clones of a given species among clinical isolates. Therefore, pure culture of each isolate has to be available. Again, a number of techniques seek to address sequence polymorphisms of strains or clones. As more such polymorphisms are included into the comparison, as higher discriminatory power can be achieved. Therefore, it is sometimes recommended to apply at least two independent techniques in a given array of isolates to verify the results and increase the discriminatory power.

\section{Electrophoretic Karyotyping (EK)}

Most fungal species display chromosome-length polymorphism, which results from unequal chromosomal rearrangements or from chromosome breakage and healing ${ }^{53}$. Sequences that cause these unequal rearrangements are mainly transposable elements and other dispersed repeats. Chromosome-length polymorphisms can be assessed by electrophoretic karyotyping, exploiting a modified type of electrophoresis. During conventional electrophoresis, fragments longer than $50 \mathrm{~kb}$ show the same mobility and remain unseparated. Pulse Field Gel Electrophoresis (PFGE) allows separation of extremely large DNA fragments or even whole chromosomes in agarose gel using an alternating electric field. In order to avoid mechanical breakage of DNA molecules during common extraction procedures, intact cells are first embedded into an agarose block and lysis is carried out in a plug of agarose excised from the initial block. The agarose matrix keeps the DNA molecules intact, in place, while allowing the reagents to diffuse freely. A plug can be incubated with detergents and enzymes to remove cellular components from the DNA. Then the plug is inserted into the gel and intact chromosomes migrate from the plug into the gel during 
electrophoresis. After each change of polarity of the current during pulsed-field gel electrophoresis, DNA coils reorient and move in a different direction. This helps them to pass through the gel. With each reorientation of the electric field, smaller sized DNA molecules realign and move in the new direction more quickly than the larger ones. Thus, the larger DNA molecules lag behind which contributes to size-separation of individual chromosomes. Chromosome sizes can vary greatly between different Candida strains, thus resulting in various banding patterns known as electrophoretic karyotypes. Evaluation of differences in banding patterns can be performed visually or can be computer-assisted. If chromosomal length polymorphism is not satisfactorily discriminatory, chromosomes can be digested by rare-cutting restriction endonucleases prior to electrophoresis, to get several variable large DNA fragments. Although the equipment needed for PFGE is rather expensive and sample preparation is labour-intensive, tedious and not suitable for analysis of large numbers of samples, EK is a well-established method in Candida spp. typing ${ }^{54}$. It has been successfully used to differentiate strains of $C$. albicans, $C$. lusitaniae, $C$. parapsilosis, $C$. tropicalis and C. glabrata $^{55-59}$, and to distinguish C. albicans from the phenotypically close species $C$. dubliniensis ${ }^{60}$. It also performed well when compared to other typing techniques ${ }^{61}$.

\section{Restriction analysis (REA)}

In this technique, genomic DNA is typically cleaved by a frequently cutting restriction endonuclease to result in sequence-dependent restriction fragment length polymorphism (RFLP). This can be visualised by separating the fragments yielded using common agarose gel electrophoresis. The resulting banding patterns show interstrain variations as a result of the polymorphic nature of restriction site sequences or as a result of deletions and insertions in the DNA stretches between cleaving sites. Restriction analysis is rapid, easy, inexpensive, but restriction patterns are very complex and therefore difficult to compare. The majority of intense bands in an RFLP pattern represents rDNA sequences and mitochondrial DNA sequences; these fragments do not provide enough information to assess the relatedness of moderately related isolates. For easier comparison, separated fragments can be transferred onto a membrane and hybridised with a labelled fingerprinting probe that will recognize relatively few fragments of restricted DNA. Multi-copy probes designed to bind repeat sequences dispersed throughout the genome (e.g. RNA genes, mitochondrial DNA sequences and repetitive sequences) were applied ${ }^{62}$. In contrast to bacteria, endonuclease digestion of ribosomal cistrons generates fragments of similar relative size in yeasts, resulting in a simple Southern blot hybridisation pattern, which is low in resolution for strain discrimination. ${ }^{63}$ Fungal rRNA and mitochondrial probes therefore have not been generally used in broad epidemiological studies ${ }^{62}$. Use of fragments containing repetitive genomic sequences as probes, e.g. the $\mathrm{Ca} 3$ probe, has been more successful ${ }^{64}$. Synthetic sequences derived from microsatellites have also been used to hybridise to hypervariable loci of fungal DNA cut with restriction endonuclease ${ }^{65}$. The locus of interest can also be amplified using gene-specific primers and then subjected to REA ${ }^{66}$. Trost et al. ${ }^{67}$ evaluated identification and strain characterization of clinically relevant Candida species by amplification of intergenic spacers ITS1 and ITS2 followed by evaluation of RFLP of PCR products after sequence-specific enzymatic cleavage.

\section{Random Amplified Polymorphic DNA (RAPD) or Arbi- trarily primed PCR (AP-PCR)}

Two groups originally developed this technique independently ${ }^{68,69}$. Although the term AP-PCR may better fit the principle of the technique, the term RAPD (pronounced rapid) is more widely used because of its simplicity. RAPD is a PCR-fingerprinting technique, which employs a single short primer (typically 10 bases in length), sequence of which is chosen arbitrarily rather than based on knowledge of the targeted genomic sequence. Therefore, RAPD requires no prior knowledge of sequence of the examined organism and can be applied universally. At the beginning, a set of oligonucleotide primers of random sequences has to be screened; those with optimal performance are chosen for further analysis. Because of its short sequence, a RAPD primer is able to anneal to many locuses throughout the genome. In addition, when RAPD is performed for typing purposes, annealing occurs under low stringency conditions (typically $\left.35-40{ }^{\circ} \mathrm{C}, 2.5 \mathrm{mM} \mathrm{MgCl}\right)_{2}$. Then, a primer likewise hybridises with many additional imperfectly matched sequences with sufficient affinity. If two molecules of the same primer anneal in a proper orientation close enough for the PCR to proceed efficiently, an amplicon is generated. Several amplicons are typically generated in a complex genomic DNA, which can be visualised as a banding pattern by gel electrophoresis. Because of competition for annealing of the primer, minor inter-strain polymorphisms in annealing sites result in strain-specific variations of banding patterns. For schematic overview of the technique see Fig. 3. The majority of amplified fragments originate from unique sequences rather than from repetitive elements ${ }^{70}$. When targeting the entire genome, RAPD generally results in more complex patterns than standard PCR or RFLP and may increase the likelihood of detecting interstrain differences ${ }^{71}$. RAPD is easily designed, technically simple, economic and also faster than other typing methods. However, special emphasis should be laid on the performance of this technique, because minor differences in experimental conditions can result in different profiles, which compromises intra- and interlaboratory reproducibility of RAPD. There are many factors, that can influence the appearance or disappearance of bands, including $\mathrm{Mg}^{2+}$ concentration, primer/template concentration ratio, Taq polymerase concentration and source, the model of thermal cycler etc. ${ }^{72-74}$ RAPD applied to eukaryotes seems to be more reproducible due to the higher stability of their genomes ${ }^{72}$. To overcome reproducibility obstacles, PCR can be also targeted to specific sequences, for example microsatellite sequences, and performed at higher stringency ${ }^{75}$. RAPD combines the advantage of operational simplicity with no need of 
1. Short primer of random sequence is able to anneal at several more or less complementary sites throughout the denatured genomic DNA

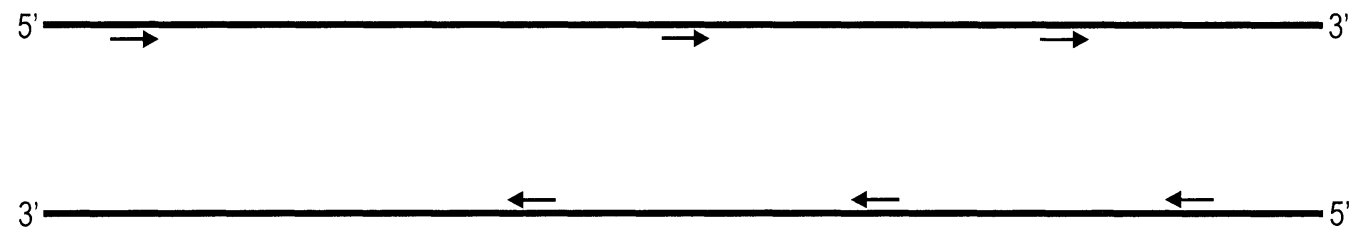

2. Sequences flanked by annealled primers are amplified by PCR
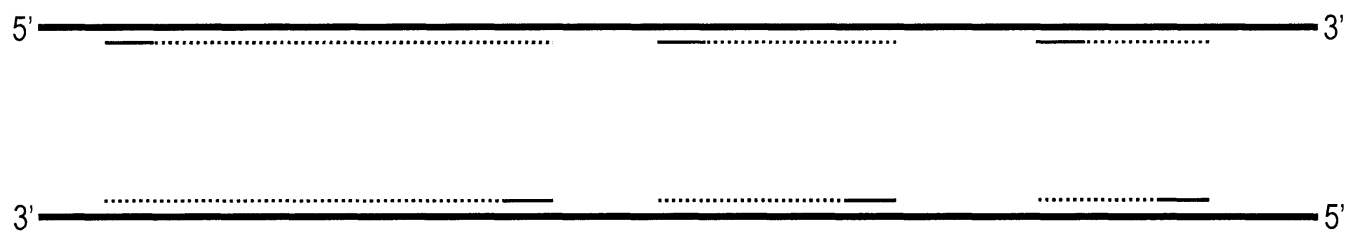

3. Because of competition of several sites for primer annealing, minor inter-strain differences in sequence of a particular site prevent or facilitate primer annealing and change the spectrum of amplified fragments

Fig. 3. Essential steps of Random Amplified Polymorphic DNA (RAPD) technique.

prior sequence data, which makes it suitable especially for typing of a collection of isolates of less studied microorganisms, when interlaboratory comparison is not required. Therefore, RAPD is the most widely used typing technique in clinical mycology. It has been repeatedly shown, that RAPD can be employed as a convenient tool for species identification as well as strain typing ${ }^{76-79}$. On the other hand, problems with possible bias during complicated comparison of banding patterns consisting of bands of variable intensity should not be denied. To overcome this, a new McRAPD approach, which takes advantage of melting analysis of RAPD amplicons, has been introduced recently ${ }^{80}$. It omits both gel electrophoresis and tedious analysis of banding patterns and directly yields numerical data, which can be subjected to automated unbiased analysis. It was first employed for rapid and accurate species identification in five pathogenic yeast species. However, when high-resolution melting device and saturating dye are used to increase its discriminatory power, it seems to be well suitable for strain typing as well (unpublished data).

\section{Amplified fragment length polymorphism (AFLP)}

Amplified fragment length polymorphism is a PCRbased DNA fingerprinting technique ${ }^{81}$. In short, the AFLP procedure usually starts by digestion of genomic DNA using two restriction enzymes (generally a hexa-cutter and a tetra-cutter) followed by ligation of double-stranded adapters to the ends of the restriction fragments. Afterwards, amplification of the restriction fragments by PCR using two primers complementary to the adapter- and restriction site sequences takes place. To reduce the amount of resulting amplicons, one to three selective nucleotides are usually added to the 3 '-ends of primers. Then, a subset of restriction fragments, harbouring complementary sequence to the primer extension adjacent to the restriction site, is amplified. Finally, amplified restriction fragments are separated by gel electrophoresis and analysed. Primers may be labelled by fluorescent tags enabling a computer-based automated sequence analyser to read the polyacrylamide gel electrophoretic patterns (Fluorescent Amplified Fragment Length Polymorphism, FAFLP). For schematic overview of the technique see Fig. 4. A typical AFLP fingerprint represents between 50-100 bands, which greatly increases the discriminatory power of AFLP and this facilitates its use in epidemiological studies. On the other hand, the expense and expertise needed discourage its routine use. Like RAPD and RFLP, AFLP requires no prior sequence information. However, compared to RAPD, specific primers and stringent annealing temperature ensure that AFLP is a highly reproducible and robust method, whereas compared to RFLP, fingerprints obtained with AFLP are more informative, easier to read and reading can be automated. At first, AFLP was used for bacteria typing in microbiology ${ }^{82}$. More recently, pathogenic Candida species identification ${ }^{83}$ and typing ${ }^{84}$ have also been reported.

\section{DNA sequencing}

Obviously, the most accurate way to compare two individuals, strains or clones is to sequence their entire genomes. Of course, such an approach is impracticable for routine use. Instead, parts of a selected fungal gene can be amplified and resulting sequences can be compared ${ }^{85}$. However, focusing on just one variable fragment can hardly provide enough data for strain typing and is usually 
1. Genomic DNA is cutted into many fragments by a frequently-cutting restriction endonuclease like in REA

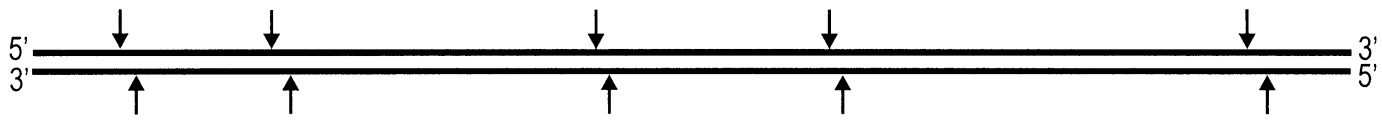

2. Adaptors of known sequence are ligated to complementary cohesive ends of the fragments
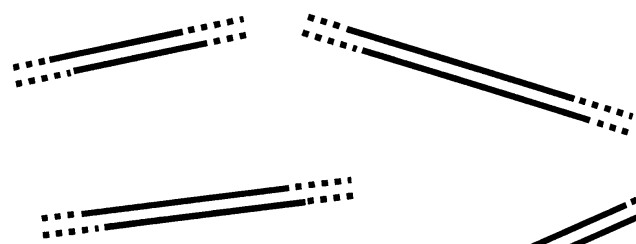

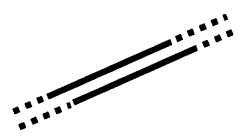

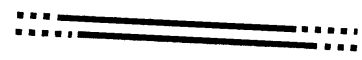

3. Primers complementary to the sequence of adaptors with 1 to 3 additional arbitrary bases (e.g. adapator + AT at 3 '-end) anneal to a subset of denatured fragments during PCR, resulting in their amplification
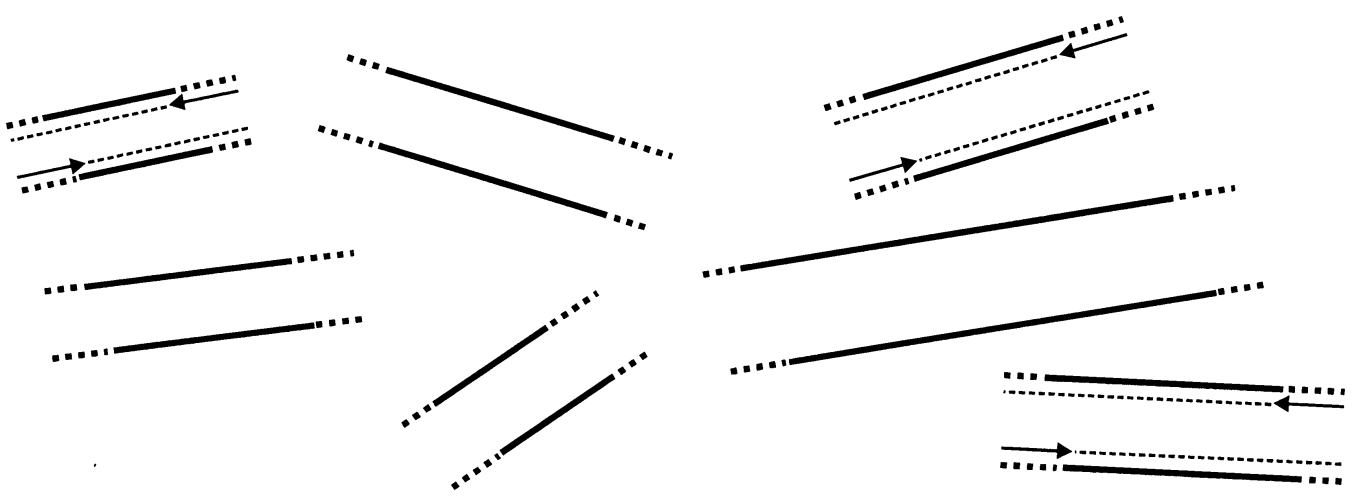

3. Amount of each amplified fragment reaches roughly equal level in the saturation phase of specific PCR amplification, which results in banding patterns much easier to read compared to REA. Alternatively, primers can be labelled by a fluorescent tag and amplified fragments subsequently analysed using capillary electrophoresis.

Fig. 4. Essential steps of Amplified Fragment Length Polymorphism (AFLP) technique.

suitable for species identification only. Coleman et al. ${ }^{86}$ studied a fragment of the V3 variable region of the large ribosomal subunit genes from $C$. dubliniensis isolates and found out that it was significantly different from the other species analysed. Including more locuses into sequencing and consecutive comparison can increase the discriminatory power. Botterel et al. ${ }^{87}$ used sequencing of three polymorphic microsatellite markers to $C$. albicans typing. To date, the most complex and promising use of sequencing for typing purposes is represented by the Multi Locus Sequence Typing (MLST) approach. MLST focuses on the nucleotide polymorphism of internal fragments of several housekeeping genes, where each unique allele combination determines a sequence type of strain. Fragments of the housekeeping genes are first amplified by PCR and then sequenced. This approach has many advantages - it provides unambiguous, portable and easy to standardize results. Absolute interlaboratory reproducibility can be achieved, enabling global epidemiological studies. The MLST approach is developed continuously as an open platform (http://www.mlst.net) (ref. $\left.{ }^{88}\right)$. Bougnoux et al. ${ }^{89}$ investigated the potential value of MLST for characterization of clinical isolates of C. albicans and found it a highly resolving and stable method. MLST was also compared to other fingerprinting methods already established for $C$. albicans by Robles et al. ${ }^{90}$ MLST system for strain differentiation has been already set up for $C$. tropicalis, C. glabrata and $C$. albicans ${ }^{91}$. Although the technique is currently not feasible for most laboratories, increasingly user-friendly automation together with cutting of costs due to newly emerging technologies (e.g. pyrosequencing) promise broader availability in the future. 


\section{DNA-microarrays}

Microarray-based systems offer an attractive outlook not only for the future of strain typing. They a offer high level of sensitivity, specificity and throughput capacity, without requiring a prior $i$ knowledge of specific sequences. Chips or microarrays are high-density microscopic sets of oligonucleotide probes immobilized on solid surface, to which nucleic acid samples are hybridised. Perfectly matched sequences from the sample hybridise more efficiently to the corresponding oligomers on the array and give stronger signal than mismatched bound sequences. The final signal is detected by high-resolution fluorescent scanning and analysed by computer software, thus enabling automation and standardization ${ }^{92}$. Easier management of the vast data generated and reduction of the costs of DNA-chips are only a matter of time. Then, microarrays surely will move from the research area to clinical practice. For typing purposes, microarrays can be directed to identify the presence and quantity of different sequence variants of specific genes or regions, e.g. rRNA genes, internal transcribed spacers (ITSs) in particular. Ongoing sequencing projects in pathogenic yeasts will also soon enable quite straightforward designing of whole-genome DNA microarrays ${ }^{93}$. The use of microarrays for microbial fingerprinting has been already reported for Salmonella enterica isolates ${ }^{94}$, for closely related Xanthomonas pathovars ${ }^{95}$ and Mycobacterium species $^{96}$. Rapid automated performance of tens of thousands of hybridisation assays on a tiny chip represents the strongest point of this technology.

\section{CONCLUSION}

To conclude, both yeast species identification and strain typing mainly relies on several modifications of two basic technologies - amplification of a DNA fragment followed by its analysis by different means, or, hybridisation of the total genomic DNA to a set of probes. It is not easy to foresee, which of these approaches will ultimately prevail. Most probably, the repertoire of techniques applied will be reduced only partly, because different techniques can best match different particular needs. Both the costs, easy operation and the reproducibility and resolving power will be considered for particular applications of different techniques. Also, both a trend towards better performance of less reproducible or less discriminatory but cost-effective techniques and a trend towards lower costs of highly reproducible and discriminatory but rather expensive techniques can be clearly observed. There is no doubt that PCR will be continued as the core of rapid detection and identification techniques. Due to its low costs and potential for automation, high resolution melting analysis (HRMA) promises to bring outstanding progress in post-PCR analysis in the near future. Melting analysis has already been applied in yeast species identification ${ }^{80}$ and our preliminary data show, that it is also suitable for improving the potential of RAPD typing. Furthermore, the potential of HRMA to at least partly substitute for sequencing in MLST can be envisaged, possibly establishing a new Multi Locus Melting Typing (MLMT) approach. This should bring the merits of these technologies even closer to all routine laboratories in near future. In addition, the DNA-microarrays technology surely has the potential to revolutionize DNA-based diagnostics also in the field of clinical mycology in the more distant future.

\section{ACKNOWLEDGEMENT}

Ministry of Health, Czech Republic, supported this work (NR8365-4/2005).

\section{REFERENCES}

1. Dignani MC, Solomkin JS, Anaissie EJ. Candida. In: Anaissie EJ, McGinnis MR, Pfaller MA, editors. Clinical mycology. Elsevier Science, Philadelphia 2003. p. 195-239.

2. Wenzel RP. (1995) Nosocomial candidemia: risk factors and attributable mortality. Clin Infect Dis 20, 1531-4.

3. Jarvis WR. (1995) Epidemiology of nosocomial fungal infections, whith emphasis on Candida species. Clin Infect Dis 20, 1526-30.

4. Pfaller MA. (1994) Epidemiology and control of fungal infections. Clin Infect Dis 19, 8-13.

5. Morrell M, Fraser VJ, Kollef MH. (2005) Delaying the empiric treatment of Candida bloodstream infection until positive blood culture results are obtained: a potential risk factor for hospital mortality. Antimicrob Agents Chemother 49, 3640-5.

6. de Marie S. (2000) New developments in the diagnosis and management of invasive fungal infections. Haematologica 85, 88-93.

7. Nguyen MH, Peacock JE, Morris AJ, Tanner DC, Nguyen ML, Snydman DR, Wagener MM, Rinaldi MG, Yu VL. (1996) The changing face of candidemia: emergence of non-Candida albicans species and antifungal resistance. Am J Med 100, 617-23.

8. Krcmery V, Barnes AJ. (2002) Non-albicans Candida spp. causing fungaemia: pathogenicity and antifungal resistance. J Hosp Infect 50, 243-60.

9. Capoor MR, Nair D, Deb M, Verma PK, Srivastava L, Aggarwal P. (2005) Emergence of non-albicans Candida species and antifungal resistance in a tertiary care hospital. Jpn J Infect Dis 58, 344-8.

10. Pfaller MA. (1996) Nosocomial candidiasis: emerging species, reservoirs and modes of transmission. Clin Infect Dis 22, 89-94.

11. Tenover FC, Arbeit RD, Goering RV. (1997) How to select and interpret molecular strain typing methods for epidemiological studies of bacterial infections: a review for healthcare epidemiologists. Infect Control Hosp Epidemiol 18, 426-39.

12. Soll DR. (1992) High-frequency switching in Candida albicans. Clin Microbiol Rev 5, 183-203.

13. Reiss E, Tanaka K, Bruker G, Chazalet V, Coleman D, Debeaupuis JP, Hanazawa R, Latge JP, Lortholary J, Makimura K, Morrison CJ, Murayama SY, Naoe S, Paris S, Sarfati J, Shibuya K, Sullivan D, Uchida K, Yamaguchi H. (1998) Molecular diagnosis and epidemiology of fungal infections. Med Mycol 36, 249-57.

14. Flahaut M, Sanglard D, Monod M, Bille J, Rossier M (1998) Rapid detection of Candida albicans in clinical samples by DNA amplification of common regions from $C$. albicans-secreted aspartic proteinase genes. J Clin Microbiol 36, 395-401.

15. Burgener-Kairuz P, Zuber JP, Jaunin P, Buchman TG, Bille J, Rossier M. (1994) Rapid detection and identification of Candida albicans and Torulopsis (Candida) glabrata in clinical specimens by species specific nested PCR amplification of a cytochrome P450 lanosterol-alpha-demethylase (L1A1) gene fragment. J Clin Microbiol 32, 1902-7.

16. Kan VL. (1993) Polymerase chain reaction for the diagnosis of candidaemia. J Infect Dis 168, 779-83.

17. Crampin AC, Matthews RC. (1993) Application of the polymerase chain reaction to the diagnosis of candidosis by amplification of an HSP 90 gene fragment. J Med Microbiol 39, 233-8. 
18. Kanbe T, Horii T, Arishima T, Ozeki M, Kikuchi A. (2002) PCRbased identification of pathogenic Candida species using primer mixes specific to Candida DNA topoisomerase II genes. Yeast 19, 973-89.

19. Bougnoux ME, Dupont C, Mateo J, Saulnier P, Faivre V, Payen D, Nicolas-Chanoine MH. (1999) Serum is more suitable than whole blood for diagnosis of systemic candidiasis by nested PCR. J Clin Microbiol 37, 925-30.

20. Louie M, Louie L, Simor AE. (2000) The role of DNA amplification technology in the diagnosis of infectious diseases. CMAJ 163 301-9.

21. Loeffler J, Hebart H, Bialek R, Hagmeyer L, Schmidt D, Serey FP, Hartmann M, Eucker J, Einsele H. (1999) Contaminations occuring in fungal PCR assays. J Clin Microbiol 37, 1200-2.

22. Kwok S, Higuchi R. (1989) Avoiding false positives with PCR Nature 339, 237-8.

23. Lind K, Stahlberg A, Zoric N, Kubista M (2006) Combining sequence-specific probes and DNA binding dyes in real-time PCR for specific nucleic acid quantification and melting curve analysis. BioTechniques 40, 315-319.

24. Pryce TM, Kay ID, Palladino S, Heath CH. (2003) Real-time automated polymerase chain reaction (PCR) to detect Candida albicans and Aspergillus fumigatus DNA in whole blood from high-risk patients. Mycology 47, 487-96.

25. Hsu MC, Chen KW, Lo HJ, Chen YC, Liao MH, Lin YH, Li SY (2003) Species identification of medically important fungi by use of real-time LightCycler PCR. J Med Microbiol 52, 1071-6.

26. White PL, Shetty A, Barnes RA. (2003) Detection of seven Candida species using the LightCycler system. J Med Micobiol 52, 229-38.

27. Selvarangan R, Bui U, Limaye AP, Cookson. (2003) Rapid identification of commonly encountered Candida species directly from blood culture bottles. J Clin Microbiol 41, 5660-4.

28. Guiver M, Levi K, Oppenheim BA. (2001) Rapid identification of Candida species by TaqMan PCR. J Clin Pathol 54, 362-6.

29. Mackay IM. (2004) Real-time PCR in the microbiology laboratory. Clin Microbiol Infect 10, 190-212.

30. Bu R, Sathiapalan RK, Ibrahim MM, Al-Mohsen I, Almodovar E, Gutierrez MI, Bhatia K. (2005) Monochrome LightCycler PCR assay for detection and quantification of five common species of Candida and Aspergillus. J Med Microbiol 54, 243-8.

31. Jung M, Dritschilo A, Kasid U. (1992) Reliable and efficient direct sequencing of PCR-amplified double-stranded genomic DNA template. PCR Methods Appl 1, 171-4.

32. Hall L, Wohlfiel S, Roberts GD. (2003) Experience with the MicroSeq D2 large-subunit ribosomal DNA sequencing kit for identification of commonly encountered, clinically important yeast species. J Clin Microbiol 41, 5099-102.

33. Marino MA, Turni LA, Del Rio SA, Williams PE. (1994) Molecular size determinations of DNA restriction fragments and polymerase chain reaction products using capillary gel electrophoresis. $\mathbf{J}$ Chromatogr A 676, 185-9.

34. Chen YC, Eisner JD, Kattar MM, Rassoulian-Barrett SL, LaFe K, Yarfitz SL, Limaye AP, Cookson BT. (2000) Identification of medically important yeasts using PCR-based detection of DNA sequence polymorphisms in the internal transcribed spacer 2 region of the rRNA genes. J Clin Microbiol 38, 2302-10.

35. Morace G, Sanguinetti M, Posteraro B, Lo Cascio G, Fadda G. (1997) Identification of various medically important Candida species in clinical specimens by PCR-restriction enzyme analysis. J Clin Microbiol 35, 667-72.

36. Dendis M, Horváth R, Michálek J, Růžička F, Grijalva M, Bartoš M, Benedík J. (2003) PCR-RFLP detection and species identification of fungal pathogens in patients with febrile neutropenia. Clin Microbiol Infect 9, 1191-202.

37. Jaeckel S, Epplen JT, Kauth M, Miterski B, Tschentscher F, Epplen C. (1998) Polymerase-chain reaction-single strand conformation polymorphism or how to detect reliably and efficiently each sequence variation in many samples and many genes. Electrophoresis 19, 3055-61
38. Hui M, Ip M, Chan PK, Chin ML, Cheng AF. (2000) Rapid identification of medically important Candida to species level by polymerase chain reaction and single-strand conformational polymorphism. Diagn Microbiol Infect Dis 38, 95-9.

39. Fujita S, Lasker BA, Lott TJ, Reiss E, Morrison CJ. (1995) Microtitration plate enzyme immunoassay to detect PCR-amplified DNA from Candida species in blood. J Clin Microbiol 33, 962-7.

40. Ririe KM, Rasmussen RP, Wittwer CT. (1997) Product differentiation by analysis of DNA melting curves during the polymerase chain reaction. Anal Biochem 245, 154-60.

41. Herrmann MG, Durtschi JD, Bromley LK, Wittwer CT, Voelkerding KV. (2006) Amplicon DNA melting analysis for mutation scanning and genotyping: cross-platform comparison of instruments and dyes. Clin Chem 52, 494-503.

42. Odell ID, Cloud JL, Seipp M, Wittwer CT. (2005) Rapid species identification within the Mycobacterium chelonae-abscessus group by high-resolution melting analysis of hsp65 PCR products. Am J Clin Pathol 123, 96-101.

43. Compton J. (1991) Nucleic acid sequence-based amplification. Nature 350, 91-2.

44. Kievits T, Van Gemen B, Van Strijp D, Schukking R, Dircks M, Andriaanse H, Malek L, Sooknanan R, Lens P. (1991) NASBA isothermal enzymatic in vitro nucleic acid amplification optimized for the diagnosis of HIV-1 infection. J Virol Methods 35, 273-86.

45. Widjojoatmodjo MN, Borst A, Schukking RAF, Box ATA, Tacken NMM, Gemen BV, Verhoef J, Top B, Fluit AC. (1999) Nucleic acid sequence-based amplification (NASBA) detection of medically important Candida species. J Microbiol Methods 38, 81-90.

46. Loeffler J, Dorn C, Hebart H, Cox P, Magga S, Einsele H. (2003) Development and evaluation of the Nuclisens Basic Kit NASBA for the detection of RNA from Candida species frequently resistant to antifungal drugs. Diagn Microbiol Infect Dis 45, 217-20.

47. Lischewski A, Kretschmar M, Hof H, Amann R, Hacker J, Morschhäuser J. (1997) Detection and identification of Candida species in experimentally infected tissue and human blood by rRNA-specific fluorescent in situ hybridization. J Clin Microbiol 35, 2943-8.

48. Kempf VAJ, Trebesius K, Autenrieth IB. (2000) Fluorescent in situ hybridization allows rapid identification of microorganisms in blood cultures. J Clin Microbiol 38, 830-8.

49. Rigby S, Procop GW, Haase G, Wilson D, Hall G, Kurtzman C, Oliveira K, Oy SV, Hyldig-Nielsen JJ, Coull J, Stender H. (2002) Flurescence in situ hybridization with peptide nucleic acid probes for rapid identification of Candida albicans directly from blood culture bottles. J Clin Microbiol 40, 2182-6.

50. Wilson DA, Joyce MJ, Hall LS, Reller LB, Roberts GD, Hall GS, Alexander BD, Procop GW. (2005) Multicenter evaluation of a Candida albicans peptide nucleic acid fluorescent in situ hybridization probe for characterization of yeast isolates from blood cultures. J Clin Microbiol 43, 2909-12.

51. Alexander BD, Ashley ED, Reller LB, Reed SD. (2006) Cost savings with implementation of PNA FISH testing for identification of Candida albicans in blood cultures. Diagn Microbiol Infect Dis (in press)

52. Oliviera K, Haase G, Kurtzman C, Hyldig-Nielsen JJ, Stender H. (2001) Differentiation of Candida albicans and Candida dubliniensis by fluorescent in situ hybridization with peptide nucleic acid probes. J Clin Microbiol 39, 4138-41.

53. Zolan ME. (1995) Chromosome-length polymorphism in fungi. Microbiol Rev 59, 686-98.

54. Monod M, Porchet S, Baudraz-Rosselet F, Frenk E. (1990) The identification of pathogenic yeast strains by electrophoretic analysis of their chromosomes. J Med Microbiol 29, 123-9.

55. Espinel-Ingroff A, Vazquez JA, Boikov D, Pfaller MA. (1999) Evaluation of DNA-based typing procedures for strain categorization of Candida spp. Diagn Microbiol Infect Dis 33, 231-9.

56. Asakura K, Iwaguchi SI, Homma M, Sukai T, Higashide K, Tanaka K. (1991) Electrophoretic karyotypes of clinically isolated yeasts of Candida albicans and C. glabrata. J Gen Microbiol 137, 2531-8. 
57. Carruba G, Pontieri E, De Bernardis F, Martino P, Cassone A (1991) DNA fingerprinting and electrophoretic karyotypes of environmental and clinical isolates of Candida parapsilosis. J Clin Microbiol 29, 916-22.

58. Magee BB, Magee PT. (1987) Electrophoretic karyotypes and chromosome numbers in Candida species. J Gen Microbiol 133, 425-30.

59. Merz WG, Connelly C, Hieter P. (1988) Variation of electrophoretic karyotype among clinical isolates of Candida albicans. J Clin Microbiol 26, 842-5.

60. Sullivan D, Coleman D. (1998) Candida dubliniensis: characteristics and identification. J Clin Microbiol 36, 329-34.

61. Lopez-Ribot JL, McAtee RK, Kirkpatrick WR, Perea S, Patterson TF. (2000) Comparison of DNA-based typing methods to assess genetic diversity and relatedness among Candida albicans clinical isolates. Rev Iberoam Micol 17, 49-54.

62. Soll DR. (2000) The ins and outs of DNA fingerprinting of infectious fungi. Clin Microbiol Rev 13, 332-70.

63. Gil-Lamaignere C, Roilides E, Hacker J, Müller FMC. (2003) Molecular typing of fungi-a critical review of the possibilities and limitations of currently and future methods. Clin Microbiol Infect 9, 172-85.

64. Anderson J, Srikantha T, Morrow B, Miyasaki SH, White TC, Agabian N, Schmid J, Soll DR. (1993) Characterization and partial nucleotide sequence of the DNA fingerprinting probe $\mathrm{Ca} 3$ of Candida albicans. J Clin Microbiol 31, 1472-80.

65. Sullivan DJ, Bennett D, Henman M, Harwood P, Flint S, Mulkahy F, Shanley D, Coleman D. (1993) Oligonucleotide fingerprinting of isolates of Candida species other than C. albicans and of atypical Candida species from human immunodeficiency virus-positive and AIDS patients. J Clin Microbiol 31, 2124-33.

66. Olive DM, Bean P. (1999) Principles and applications of methods for DNA-based typing of microbial organisms. J Clin Microb 37 1661-9.

67. Trost A, Graf B, Eucker J, Sezer O, Possinger K, Gobel UB, Adam K. (2004) Identification of clinically relevant yeasts by PCR/RFLP. J Microbiol Methods 56, 201-11.

68. Williams JGK, Kubelik AR, Livak KJ, Rafalski JA, Tingey SV. (1990) DNA polymorphisms amplified by arbitrary primers are useful as genetic markers. Nucleic Acids Res 18, 1631-5.

69. Welsh J, McClelland M. (1991) Genomic fingerprinting with APPCR using pairwise combinations of primers: Application to genetic mapping of the mouse. Nucleic Acids Res 19, 861-6.

70. Welsh J, Ralph D, McClelland. DNA and RNA fingerprinting using arbitrarily primed PCR. In: Innis MA, Gelfand DH, Sninsky JJ, editors. PCR strategies. Academic Press, San Diego/New York 1995. p. 249-76

71. Swaminathan B, Barrett TJ. (1995) Amplification methods for epidemiologic investigations of infectious diseases. J Microbio Methods 23, 129-39.

72. Tyler KD, Wang G, Tyler SD, Johnson WM. (1997) Factors affecting reliability and reproducibility of amplification-based DNA fingerprint of representative bacterial pathogens. J Clin Microbiol 35, 339-46.

73. Penner GA, Bush A, Wise R, Kim W, Domier L, Kasha K, Laroche A, Scoles G, Molnar SJ, Fedak G. (1993) Reproducibility of random amplified polymorphic DNA (RAPD) analysis among laboratories. PCR Methods Appl 2, 341-5.

74. Meunier JR, Grimont PA. (1993) Factors affecting reproducibility of random amplified polymorphic DNA fingerprinting. Res Microbiol 144, 373-9.

75. Shemer R, Weissman Z, Hashman N, Kornitzer D. (2001) A highly polymorphic degenerate microsatellite for molecular strain typing of Candida krusei. Microbiology 147, 2021-8.

76. Lehmann PF, Lin D, Lasker BA. (1992) Genotypic identification and characterization of species and strains within the genus Candida by using random amplified polymorphic DNA. J Clin Microbiol 30, 3249-54.

77. Liu D, Coloe S, Jones SL, Baird R, Pedersen J. (1996) Genetic speciation of Candida isolates by arbitrarily primed polymerase chain reaction. FEMS Microbiol Lett 145, 23-6.
78. Steffan P, Vazquez JA, Boikov D, Xu C, Sobel JD, Atkins RA. (1997) Identification of Candida species by randomly amplified polymorphic DNA fingerprinting of colony lysates. J Clin Microbiol 35, 2031-9.

79. Bautista-Munoz C, Boldo XM, Villa-Tanaca L, HernandezRodriguez C. (2003) Identification of Candida spp. by randomly amplified polymorphic DNA analysis and differentiation between Candida albicans and Candida dubliniensis by direct PCR methods. J Clin Microbiol 41, 414-20.

80. Plachý R, Hamal P, Raclavský V. (2005) McRAPD as a new approach to rapid and accurate identification of pathogenic yeasts. $\mathbf{J}$ Microbiol Methods 60, 107-13.

81. Vos P, Hogers R, Bleeker M, Reijans M, van der Lee T, Hornes M, Frijters A, Pot J, Peleman J, Kuiper M, Zabeau M. (1995) AFLP: a new technique for DNA fingerprinting. Nucleic Acids Res 23, 4407-14.

82. Lin JJ, Kuo J, Ma J. (1996) A PCR-based DNA fingerprinting technique: AFLP for molecular typing of bacteria. Nucleic Acids Res 24, 3649-50.

83. Borst A, Theelen B, Reinders E, Boekhout T, Fluit AC, Savelkoul PHM. (2003) Use of amplified fragment length polymorphism analysis to identify medically important Candida spp., including C. dubliniensis. J Clin Microbiol 41, 1357-62.

84. Ball LM, Bes MA, Theelen B, Boekhout T, Egeler RM, Kuijper EJ (2004) Significance of amplified fragment length polymorphism in identification and epidemiological examination of Candida species colonization in children undergoing allogenic stem cell transplantation. J Clin Microbiol 42, 1673-9.

85. Chen SCA, Halliday CL, Meyer W. (2002) A review of nucleic acidbased diagnostic tests for systemic mycoses with an emphasis on polymerase chain reaction-based assays. Med Mycol 40, 333-57.

86. Coleman D, Sullivan D, Harrington B, Haynes K, Henman M, Shanley D, Bennet D, Moran G, McCreary C, O’Neill L. (1997) Molecular and phenotypic analysis of Candida dubliniensis: a recently identified species linked with oral candidosis in HIV-infected patients. Oral Dis 3, 96-101.

87. Botterel F, Desterke C, Costa C, Bretagne S. (2001) Analysis of microsatellite markers of Candida albicans used for rapid typing. J Clin Microbiol 39, 4076-81.

88. Aanensen DM, Spratt BG. (2005) The multilocus sequence typing network: mlst.net. Nucleic Acids Res 33, W728-W733.

89. Bougnoux ME, Morand S, d'Enfert C. (2002) Usefulness of multilocus sequence typing for characterization of clinical isolates of Candida albicans. J Clin Microbiol 40, 1290-7.

90. Robles JC, Koreen L, Park S, Perlin DS. (2004) Multilocus sequenced typing is a reliable alternative method to DNA fingerprinting for discriminating among strains of $C$. albicans. J Clin Microbiol 42, 2480-8.

91. Tavanti A, Davidson AD, Johnson EM, Maiden MC, Shaw DJ, Gow NA, Odds FC. (2005) Multilocus sequence typing for differentiation of strains of Candida tropicalis. J Clin Microbiol 43 , 5593-600.

92. Kurella M, Hsiao LL, Yoshida T, Randall JD, Chow G, Sarang SS, Jensen RV, Gullans SR. (2001) DNA microarray analysis of complex biologic processes. J Am Soc Nephrol 12, 1072-8.

93. Cummings CA, Relman DA. (2000) Using DNA microarrays to study host-microbe interactions. Emerg Infect Dis 6, 513-25.

94. Willse A, Straub TM, Wunschel SC, Small JA, Call DR, Daly DS, Chandler DP. (2004) Quantitative oligonucleotide microarray fingerprinting of Salmonella enterica isolates. Nucleic Acids Res 32, 1848-56.

95. Kingsley MT, Straub TM, Call DR, Daly DS, Wunschel SC, Chandler DP. (2002) Fingerprinting closely related xanthomonas pathovars with random nonamer oligonucleotide microarrays. Appl Environ Microbiol 68, 6361-70.

96. Troesch A, Nguyen H, Miyada CG, Desvarenne S, Gingeras TR, Kaplan PM, Cros P, Mabilat C. (1999) Mycobacterium species identification and rifampicin resistance testing with high-density DNA probe arrays. J Clin Microbiol 37, 49-55. 